\title{
The effect of body mass index and creatinine clearance on serum trough concentration of vancomycin in adult patients
}

Yuyan Pan ${ }^{1}$, Xiaomei He${ }^{1}$, Xinyu Yao ${ }^{2}$, Xiaofeng Yang ${ }^{3}$, Fengjiao Wang ${ }^{4}$, Xinyuan Ding ${ }^{5^{*}}$ and Wenjuan Wang ${ }^{4^{*}}$ (D)

\begin{abstract}
Background: The aim of this study was to evaluate the influence of patient body mass index (BMI) and estimated creatinine clearance $(\mathrm{CrCl})$ on serum vancomycin concentrations to define a possible optimal dosage regimen in overweight patients based on data obtained during therapeutic drug monitoring.

Methods: This retrospective study used data collected from January 2017 to January 2019. Adult patients $(n=204)$ received vancomycin treatment at a dose of $1000 \mathrm{mg}$ every $12 \mathrm{~h}$ and underwent serum monitoring. Data collected included patient disease category, sex, age, height, weight, vancomycin concentrations, and serum creatinine. The $\mathrm{CrCl}$ values were estimated using the Cockcroft-Gault formula. In this study, statistical comparisons were performed on the results of patients according to serum vancomycin concentration.

Results: Serum vancomycin concentration was significantly related to BMI $(P<0.001)$ and $\mathrm{CrCl}(P<0.05)$ in adult patients. Furthermore, the trough serum vancomycin concentration showed a logarithmic correlation with BMI $(R=$ $-0.5108,95 \% \mathrm{Cl}:-0.6082$ to $-0.3982, P<0.001)$ and $\mathrm{CrCl}(R=-0.5739,95 \% \mathrm{Cl}:-0.6616$ to $-0.4707, P<0.001)$. The multivariate analysis showed that $\mathrm{BMI}$ and $\mathrm{CrCl}$ are independent contributors to the trough vancomycin concentration. Moreover, some of the patients with higher BMl $\left(\geq 24 \mathrm{~kg} / \mathrm{m}^{2}\right)$ met the goal trough concentration after an adjustment from $1000 \mathrm{mg}$ every $12 \mathrm{~h}$ to $1000 \mathrm{mg}$ every $8 \mathrm{~h}$.

Conclusions: Serum vancomycin concentration decreases progressively with increasing BMl and the augmentation in $\mathrm{CrCl}$ in adult patients. The trough concentration of vancomycin should be continuously monitored for patients with a BMI $\geq 24 \mathrm{~kg} / \mathrm{m}^{2}$, and the dosage regimen should be adjusted to reach the target trough concentration in these patients to reduce the impact of BMI.
\end{abstract}

Keywords: Therapeutic drug monitoring, Vancomycin, Body mass index, Creatinine clearance

\footnotetext{
* Correspondence: aladdine@163.com; wangwenjuan1110@163.com

${ }^{5}$ Department of Pharmacy, The Affiliated Suzhou Hospital of Nanjing Medical University, Suzhou 215000, China

${ }^{4}$ Department of Pharmacy, Children's Hospital of Soochow University, Suzhou 215000, China

Full list of author information is available at the end of the article
}

(c) The Author(s). 2020 Open Access This article is licensed under a Creative Commons Attribution 4.0 International License, which permits use, sharing, adaptation, distribution and reproduction in any medium or format, as long as you give appropriate credit to the original author(s) and the source, provide a link to the Creative Commons licence, and indicate if changes were made. The images or other third party material in this article are included in the article's Creative Commons licence, unless indicated otherwise in a credit line to the material. If material is not included in the article's Creative Commons licence and your intended use is not permitted by statutory regulation or exceeds the permitted use, you will need to obtain permission directly from the copyright holder. To view a copy of this licence, visit http://creativecommons.org/licenses/by/4.0/ The Creative Commons Public Domain Dedication waiver (http://creativecommons.org/publicdomain/zero/1.0/) applies to the data made available in this article, unless otherwise stated in a credit line to the data. 


\section{Background}

Vancomycin is a glycopeptide antibiotic produced by Streptococcus orientalis and has been used for over half a century. Although many antibiotics have been developed and used, vancomycin remains the first-line therapy for invasive multiresistant gram-positive bacterial infections, particularly those involving methicillin-resistant Staphylococcus aureus (MRSA) [1]. As the therapeutic range is narrow for vancomycin, therapeutic drug monitoring (TDM) is necessary to maximize clinical efficacy while minimizing the risk of toxicities [2]. We generally plan vancomycin administration using the trough concentration as one measure.

The clinical guidelines recommend always keeping trough vancomycin concentrations at $>10 \mu \mathrm{g} / \mathrm{mL}$ to avoid the development of resistance, and a trough vancomycin concentration of $15-20 \mu \mathrm{g} / \mathrm{mL}$ is recommended for more serious infections [3]. As the elimination of vancomycin relies almost exclusively on glomerular filtration, renal function is one of the most important factors influencing patient exposure to vancomycin [4]. Creatinine clearance $(\mathrm{CrCl})$ is the volume of creatinine in blood plasma cleared per unit time. $\mathrm{CrCl}$ is a rapid and effective method for the measurement of renal function. In fact, it is more accurate and provides a better estimation of vancomycin pharmacokinetics to utilize patients' non-capped $\mathrm{CrCl}$ when determining a vancomycin dosing regimen [5].

A large number of studies have shown that $\mathrm{CrCl}$ is affected by factors such as age, muscle mass, diet, and proximal tubule secretion of creatinine [6-8]. In fact, early in 2009, Fernando Gerchman et al indicated that a higher body mass index (BMI) rather than body fat distribution was an independent determinant of $\mathrm{CrCl}$ in nondiabetic participants [9]. Recently, one study indicated that increased total body weight impacted $\mathrm{CrCl}$ and increased the rate of acute kidney injury among patients concurrently treated with piperacillin-tazobactam and vancomycin [10]. Pokorná and colleagues found that vancomycin pharmacokinetics were mainly influenced by actual body weight in neonates [11]. Another study reported that overweight patients have an increased glomerular filtration rate (GFR) and increased renal plasma flow [12]. Thus, the results of these studies indicate that body weight independently affects the filtering capacity of the kidneys and the pharmacokinetic properties of vancomycin. Clinical practice guidelines of the Infectious Disease Society of America (IDSA) recommended a vancomycin dose of $15-20 \mathrm{mg} / \mathrm{kg}$ (as actual body weight) every $8-12 \mathrm{~h}$ for adult patients with normal renal function, and $15 \mathrm{mg} / \mathrm{kg}$ every $6 \mathrm{~h}$ in children [13]. Hence, some clinicians increased vancomycin dosing to $\geq 4000 \mathrm{mg}$ daily. However, larger vancomycin doses are associated with a higher likelihood of vancomycin related nephrotoxicity
[14]. Base on the prescription information and the Chinese guidelines, the vancomycin dose and schedule of 1000 mg every $12 \mathrm{~h}$ for adult patients are generally used in China. However, such recommendations may be inadequate in overweight patients due to increases in vancomycin clearance and volume of distribution ( $V \mathrm{~d})$ [15]. As a result, a better assessment of renal function and dosage adjustment for vancomycin eliminated by the kidneys is needed in overweight patients [16]. We have treated many patients with relatively higher BMI in whom the serum vancomycin concentrations were found to be moderately lower based on TDM data obtained in our hospital. It is unclear whether a higher $\mathrm{BMI}$ increases $\mathrm{CrCl}$, resulting in larger vancomycin dosage requirements. In addition, to date there have been no reports focusing on the effect of both $\mathrm{BMI}$ and $\mathrm{CrCl}$ on serum vancomycin concentrations. Therefore, the purpose of our study was to determine whether both $\mathrm{BMI}$ and $\mathrm{CrCl}$ influence trough concentrations of vancomycin in adult patients.

\section{Methods \\ Patients}

A single centre retrospective cohort study was conducted at the Affiliated Changzhou No. 2 People's Hospital of Nanjing Medical University, China. Adult patients $\geq 18$ years of age admitted between January 2017 and January 2019 with suspected or documented Grampositive infections and receiving empirical vancomycin therapy were recruited. This study was approved by the Ethics Committee of the Affiliated Changzhou No. 2 People's Hospital of Nanjing Medical University. Patient data were anonymized prior to analysis. Another pharmacist, who was not participating in the study, was responsible for anonymizing these data. The following information including patient demographics such as disease category, sex, age, Acute Physiology and Chronic Health Evaluation (APACHE) II scores, height, weight, and renal function test results such as serum creatinine concentration (Scr), was collected from the patient medical records. The Scr of each patient was obtained before vancomycin administration. Other data collected included vancomycin indication, vancomycin dosing regimens, vancomycin serum trough concentrations, dates, and collection times. Patients who were pregnant, received vancomycin as perioperative antibiotic prophylaxis or on any modality of dialysis were excluded.

\section{Groups}

The prescription information for vancomycin recommends that the drug be used at dosages of $1000 \mathrm{mg}$ every $12 \mathrm{~h}$ universally, and used at dosages of $500 \mathrm{mg}$ every $12 \mathrm{~h}$ or $1000 \mathrm{mg}$ every $24 \mathrm{~h}$ in the elderly population. In fact, all the patients were treated with vancomycin at dosages of $1000 \mathrm{mg}$ every $12 \mathrm{~h}$ in this study. As 
renal function declines with age, elderly patients are more at risk for vancomycin accumulation. Therefore, patients were divided into two groups to rule out the effect of age on the results. Group A, with age $<60$ years ( $n=88$ patients), represented the youthful group, and Group B, with age $\geq 60$ years $(n=116$ patients), represented the elderly group. Underweight was defined as a $\mathrm{BMI}<18 \mathrm{~kg} / \mathrm{m}^{2}$, normal weight as a BMI of $18 \sim 23.9$ $\mathrm{kg} / \mathrm{m}^{2}$, overweight as a BMI of $24 \sim 27.9 \mathrm{~kg} / \mathrm{m}^{2}$, and obesity as a $B M I \geq 28 \mathrm{~kg} / \mathrm{m}^{2}$. Then, patients were grouped by BMI $\left(<24 \mathrm{~kg} / \mathrm{m}^{2}\right.$ and $\left.\geq 24 \mathrm{~kg} / \mathrm{m}^{2}\right)$ [17] and $\mathrm{CrCl}(<90 \mathrm{~mL} / \mathrm{min}$ and $\geq 90 \mathrm{~mL} / \mathrm{min})$ [18].

\section{Cockcroft-Gault formula: estimated $\mathrm{CrCl}$}

$\mathrm{CrCl}$ can be estimated using Scr $(\mu \mathrm{mol} / \mathrm{L})$ levels. The Cockcroft-Gault formula is the most widely used clinical method for estimating $\mathrm{CrCl}(\mathrm{mL} / \mathrm{min})$ to adjust drug dosages [19]. The resulting $\mathrm{CrCl}$ is multiplied by 0.85 if the patient is female to correct for the lower $\mathrm{CrCl}$ in females. The formulas are as follows:

$$
\begin{aligned}
& \operatorname{Crc} 1(\text { Male })=(140 \text {-age }) \times \text { weight }(\mathrm{kg}) /[0.818 \times \operatorname{Scr}(\mu \mathrm{mol} / \mathrm{L})] \\
& \operatorname{Crc} 1(\text { Female })=0.85 \times(140 \text {-age }) \times \operatorname{weight}(\mathrm{kg}) /[0.818 \times \operatorname{Scr}(\mu \mathrm{mol} / \mathrm{L})]
\end{aligned}
$$

\section{Measurement of vancomycin}

Serum vancomycin concentration was considered to have achieved steady state if $\geq 3$ half-lives (the half-life of vancomycin is $4 \sim 6 \mathrm{~h}$ [20]) had elapsed prior to first blood sampling. Dosage adjustment was performed on the subsequent days in patients with higher BMI $(\geq 24$ $\mathrm{kg} / \mathrm{m}^{2}$ ) if the trough vancomycin concentration did not reach the therapeutic range. Vancomycin serum levels were measured using the enzyme multiplied immunoassay technique (EMIT) on a Siemens Viva-E analyser (ELITechGroup B.V., Van Rensselaerweg 46,956 AV, the Netherlands). The linear range for the assay was 2$50 \mu \mathrm{g} / \mathrm{mL}$, and the limit of quantitation was $2 \mu \mathrm{g} / \mathrm{mL}$.

\section{Statistical analysis}

Prim 6.0 was used for statistical analyses. Descriptive statistics were processed for all study variables, and continuous variables are expressed as the mean (standard deviation) or median (interquartile range) where applicable. Categorical variables are expressed as numbers (percentages) and were analysed using the chi-squared test or Fisher's exact test. Linear regression analyses were performed to examine the interaction between steady-state trough concentration and $\mathrm{CrCl}$, trough concentration and BMI. A $P$-value of $<0.05$ was considered statistically significant.

\section{Results}

A total of 204 vancomycin serum concentrations were available from all patients, 133 males and 71 female patients. The mean patient age was $60.7 \pm 14.8$ years, and $65.2 \%$ were male patients. The median BMI was $23.8 \pm$ $3.0 \mathrm{~kg} / \mathrm{m}^{2}$, while the median $\mathrm{CrCl}$ was $107.5 \pm 57.8 \mathrm{~mL} /$ min. There were eight main infectious disease categories among all patients: pulmonary infection $(n=94)$, brain infection $(n=36)$, abdominal infection $(n=26)$, skin and soft tissue infection $(n=12)$, endocarditis $(n=10)$, osteoarthrosis $(n=8)$, bacteraemia $(n=8)$ and other infections $(n=10)$. The pathophysiology of critical illness can cause significant pharmacokinetic changes. As a first step to investigate the effect of infectious disease categories on the trough vancomycin concentration, the statistical analysis showed that there was no significant association of trough vancomycin concentration with disease categories $(P=0.3782$, Fig. 1a). Moreover, the median (interquartile range) APACHE-II score on admission was 11 (6-16), and there was no significant correlation between the APACHE-II score and the trough vancomycin concentration $(P=0.0887$, Fig. $1 \mathrm{~b}$ and $\mathrm{c})$. The result that the patient severity of illness had no effect on the trough vancomycin concentration was confirmed again. As acknowledged, the renal function of elderly patients is likely reduced, and we compared trough vancomycin concentrations between youthful patients and elderly patients. It was found that trough vancomycin concentrations were lower in Group A than in Group B $(11.17 \pm 8.12 \mu \mathrm{g} / \mathrm{mL}$ vs $15.39 \pm 7.18 \mu \mathrm{g} / \mathrm{mL}$, $P<0.001$, Fig. 1d), which strongly indicated that trough vancomycin concentration might be correlated with age. It is clearly that age is a risk factor for reduced renal function which in turn vancomycin concentration is affected by age. To better understand whether the trough vancomycin concentration was mediated by $\mathrm{CrCl}$ or BMI, we evaluated these two groups to eliminate the effect of age. According to the clinical guidelines of trough vancomycin concentration, a trough vancomycin concentration of $<10 \mu \mathrm{g} / \mathrm{mL}$ was assigned to low concentration and a trough vancomycin concentration of $>20 \mu \mathrm{g} / \mathrm{mL}$ was considered a high concentration. As shown in Table 1, the vancomycin concentration in Group A (age $<60$ years) was significantly related to $\mathrm{BMI}(P<0.001)$ and $\mathrm{CrCl}$ $(P=0.0162)$. However, there was no significant association of vancomycin concentration with sex. These parameters mentioned above showed the same tendencies in the elderly population composing Group B (age $\geq 60$ years). These results suggest that the trough vancomycin concentration was significantly affected by BMI and $\mathrm{CrCl}$ in both youthful patients and elderly patients.

Simultaneously, we further analysed the correlation between $\mathrm{CrCl}$ and trough vancomycin concentration, as well as the correlation between BMI and trough 


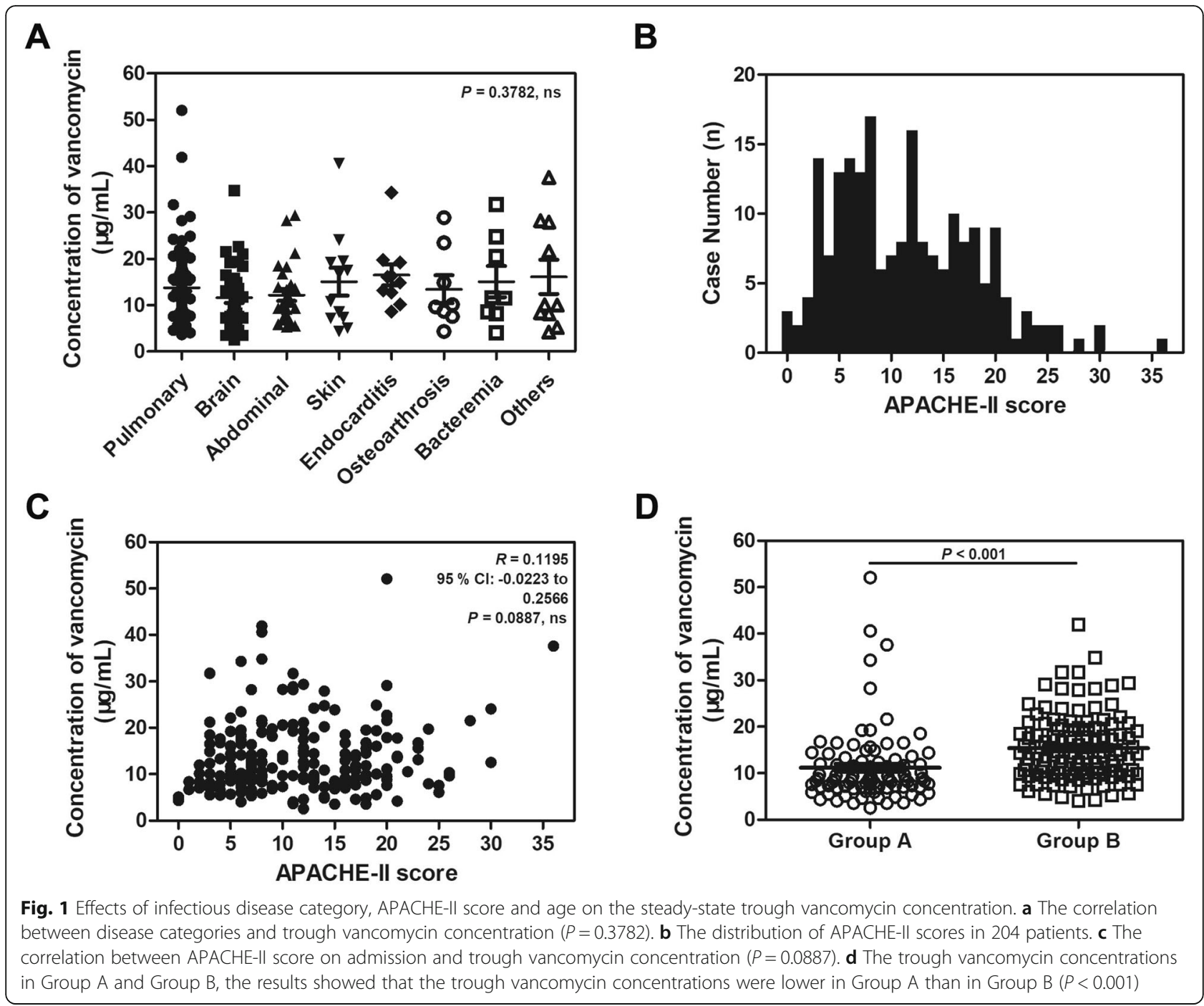

vancomycin concentration. All adult patients who received vancomycin at dosages of $1000 \mathrm{mg}$ every $12 \mathrm{~h}$ are shown in Fig. 2. As BMI and $\mathrm{CrCl}$ increased, the percentage of patients with adequate serum concentrations decreased. Most notably, trough serum vancomycin concentration showed a logarithmic correlation with BMI $(R=-0.5108,95 \%$ confidence interval $(\mathrm{CI}):-0.6082$ to - 0.3982, $P<0.001$, Fig. $2 \mathrm{a})$ and $\mathrm{CrCl}(R=-0.5739,95 \%$ CI: -0.6616 to $-0.4707, P<0.001$, Fig. $2 b)$ in all adult patients included in this study. We further classified BMI as normal $\left(\mathrm{BMI}<24 \mathrm{~kg} / \mathrm{m}^{2}\right)$ and overweight $\left(\mathrm{BMI} \geq 24 \mathrm{~kg} / \mathrm{m}^{2}\right)$ [17], $\mathrm{CrCl}$ as high $(\mathrm{CrCl} \geq 90 \mathrm{ml} / \mathrm{min})$ and low $(\mathrm{CrCl}<90 \mathrm{ml} / \mathrm{min})$ [18]. We also classified trough vancomycin concentration as high and low based on the median cut-off value. The multivariate analysis showed that both BMI and $\mathrm{CrCl}$ were significantly related to trough vancomycin concentration (Table 2). The overweight patients showed lower vancomycin concentration $(O R=0.171,95 \%$ CI 0.087 to $0.337, P<$
0.001 ), and the patients with low $\mathrm{CrCl}$ had higher vancomycin concentration $(O R=3.425,95 \%$ CI 1.770 to 6.623 , $P<0.001)$. These results indicated that both BMI and $\mathrm{CrCl}$ are independent contributors to the trough vancomycin concentration.

In addition, the dosage schedule of patients $(n=24)$ with higher BMI $\left(\geq 24 \mathrm{~kg} / \mathrm{m}^{2}, 26.88 \pm 1.71 \mathrm{~kg} / \mathrm{m}^{2}\right)$ in this study was adjusted and the time required to achieve a new steady-state was calculated. After an adjustment from $1000 \mathrm{mg}$ every $12 \mathrm{~h}$ to $1000 \mathrm{mg}$ every $8 \mathrm{~h}$, the trough concentration in three patients increased from 4.00 to $20.30 \mu \mathrm{g} / \mathrm{mL}, 7.32$ to $21.34 \mu \mathrm{g} / \mathrm{mL}$ and 5.08 to $24.31 \mu \mathrm{g} /$ $\mathrm{mL}$, while the serum concentrations achieved the goal trough concentration in $87.5 \%(n=21)$ of these patients.

\section{Discussion}

Vancomycin pharmacokinetics is highly variable even among patients with similar characteristics. In recent years, the way in which to improve the clinical efficacy 
Table 1 The correlation between serum vancomycin concentrations and characteristics of patients included in different groups

\begin{tabular}{|c|c|c|c|c|c|c|c|}
\hline \multirow[t]{2}{*}{ Groups } & \multirow{2}{*}{$\begin{array}{l}\text { Demographics and } \\
\text { characteristics }\end{array}$} & \multirow[t]{2}{*}{ Case no. } & \multicolumn{3}{|c|}{ Vancomycin concentration $(\mu \mathrm{g} / \mathrm{mL})$} & \multirow[t]{2}{*}{ Chi-square } & \multirow[t]{2}{*}{$P$-value } \\
\hline & & & $<10$ & $10 \sim 20$ & $>20$ & & \\
\hline \multirow[t]{9}{*}{ Group A (age < 60 years) } & Sex & & & & & 1.443 & 0.4861 \\
\hline & Male & 61 & 40 & 18 & 3 & & \\
\hline & Female & 27 & 15 & 9 & 3 & & \\
\hline & $\mathrm{BMI}\left(\mathrm{kg} / \mathrm{m}^{2}\right)$ & & & & & 22.450 & $<0.001^{* * *}$ \\
\hline & $<24$ & 36 & 12 & 19 & 5 & & \\
\hline & $\geq 24$ & 52 & 43 & 8 & 1 & & \\
\hline & $\mathrm{CrCl}(\mathrm{mL} / \mathrm{min})$ & & & & & 8.247 & $0.0162^{*}$ \\
\hline & $<90$ & 21 & 9 & 8 & 4 & & \\
\hline & $\geq 90$ & 67 & 46 & 19 & 2 & & \\
\hline \multirow[t]{9}{*}{ Group B (age $\geq 60$ years) } & Sex & & & & & 3.206 & 0.2013 \\
\hline & Male & 72 & 23 & 35 & 14 & & \\
\hline & Female & 44 & 8 & 23 & 13 & & \\
\hline & $\mathrm{BMI}\left(\mathrm{kg} / \mathrm{m}^{2}\right)$ & & & & & 25.360 & $<0.001^{* * *}$ \\
\hline & $<24$ & 82 & 11 & 48 & 23 & & \\
\hline & $\geq 24$ & 34 & 20 & 10 & 4 & & \\
\hline & $\mathrm{CrCl}(\mathrm{mL} / \mathrm{min})$ & & & & & 18.320 & $0.0001^{* * *}$ \\
\hline & $<90$ & 74 & 10 & 43 & 21 & & \\
\hline & $\geq 90$ & 42 & 21 & 15 & 6 & & \\
\hline
\end{tabular}

$P$ by Chi-square test, ${ }^{*} P<0.05,{ }^{* *} P<0.001$ were considered significant

of vancomycin and reduce its side effects has become the focus of clinical research. However, serum vancomycin concentrations often do not reach the target treatment level in overweight patients [21]. The World Health Organization (WHO) has published a standard for evaluating overweight and obesity in adults based on BMI [22], and there are also standard BMI values in China [17].

At present, the Chinese standard BMI cut-off points are $\geq 24 \mathrm{~kg} / \mathrm{m}^{2}$ for overweight and $\geq 28 \mathrm{~kg} / \mathrm{m}^{2}$ for obesity. It has been reported that the thresholds of BMI may be different by age group [23]. In this study, patients were divided into two groups to rule out the effect of age. Our study found that the steady-state trough vancomycin concentration was negatively correlated with BMI and $\mathrm{CrCl}$. Moreover, the elderly patients also showed a significant tendency with the same dosing regimen. In addition, we observed a significant logarithmic correlation between the steady-state trough concentration and BMI, and the steady-state trough concentration and $\mathrm{CrCl}$. The serum vancomycin concentration was strongly
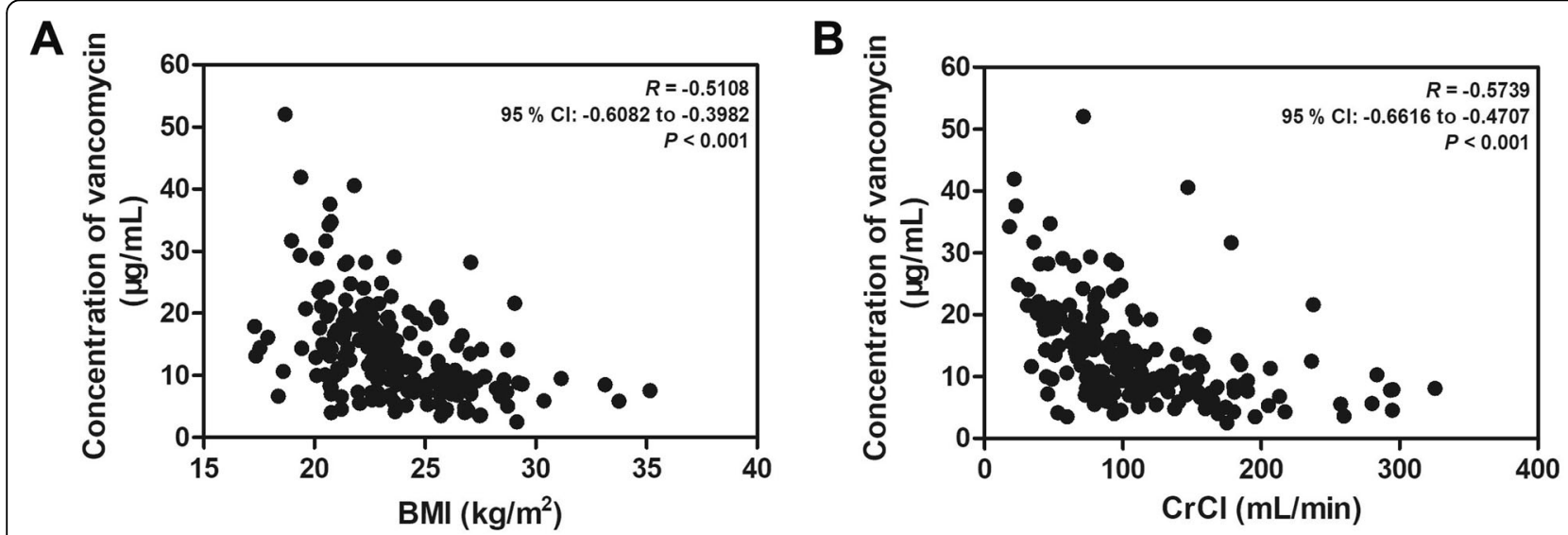

Fig. 2 The relationships between steady-state trough vancomycin concentration and BMI and $\mathrm{CrCl}$ were linear. The serum vancomycin concentration showed a logarithmic correlation with BMI $(R=-0.5108,95 \% \mathrm{Cl}$ : -0.6082 to $-0.3982, P<0.001, \mathbf{a})$ and $\mathrm{CrCl}(R=-0.5739,95 \% \mathrm{Cl}$ : -0.6616 to $-0.4707, P<0.001, \mathbf{b})$ in all adult patients included in our study 
Table 2 The multivariate analysis of $\mathrm{BMI}$ and $\mathrm{CrCl}$ related to trough vancomycin concentration

\begin{tabular}{|c|c|c|c|c|}
\hline Comparison & Variable & OR & $95 \% \mathrm{Cl}$ & $P$-value \\
\hline \multirow[t]{6}{*}{ Vancomycin concentration (High vs low) } & $\mathrm{BMI}, \mathrm{kg} / \mathrm{m}^{2}$ & & & \\
\hline & Normal $(<24)$ & Reference & $0.087 \sim 0.337$ & $<0.001^{* * *}$ \\
\hline & Overweight ( $\geq 24$ ) & 0.171 & & \\
\hline & $\mathrm{CrCl}, \mathrm{ml} / \mathrm{min}$ & & & \\
\hline & High $(\geq 90)$ & Reference & $1.770 \sim 6.623$ & $<0.001^{* * *}$ \\
\hline & Low $(<90)$ & 3.425 & & \\
\hline
\end{tabular}

*** $P<0.001$ was considered significant

associated with $\mathrm{BMI}$ and $\mathrm{CrCl}$ in all adult patients. According to our study, $\mathrm{BMI}$ and $\mathrm{CrCl}$ were both independent factors for trough vancomycin concentration. Vancomycin is a glycopeptide with hydrophilic properties, which is one of the key antibiotics used empirically in patients to treat organisms such as MRSA, enterococcus and other resistant gram-positive bacteria. The obese patients who take hydrophilic drugs have an increased $V \mathrm{~d}$ and therefore a decreased serum concentration [24]. Low vancomycin concentration can lead to treatment failure, so it is necessary to study the correlation between BMI and the concentration of vancomycin. Indeed, there were studies already had shown that $V \mathrm{~d}$ was associated with $\mathrm{BMI}$, and drug clearance (CL) had a positive correlation with $\mathrm{CrCl}[25,26]$. Hence, we speculate that the effect of BMI on vancomycin concentration may be achieved by affecting the $V \mathrm{~d}$, while the effect of $\mathrm{CrCl}$ on vancomycin concentration was mainly achieved by affecting the drug CL. Based on it, the vancomycin dosage regimen should be adjusted in a timely manner to reach the target trough concentration by considering of $\mathrm{CrCl}$ as well as BMI. In fact, we further adjusted the vancomycin dosage schedule $(1000 \mathrm{mg}$ every $8 \mathrm{~h})$ in 24 patients with $\mathrm{BMI} \geq 24 \mathrm{~kg} /$ $\mathrm{m}^{2}$, most of whom successfully achieved the goal trough concentration.

However, this study has several limitations to consider. The main limitation of the study was that it was not a strictly controlled clinical trial but a retrospective investigation with data produced in clinical settings. Other limitations must also be considered, including the small sample size. We also did not take into account the physical condition of the patients, such as a serious illness throughout their entire hospitalization. Last, we did not evaluate the clinical outcomes or adverse drug reactions of the patients.

In this study, we tried to adjust the dosage regimen for patients with $B M I \geq 24 \mathrm{~kg} / \mathrm{m}^{2}$, and the effects were mostly ideal. Therefore, the combination of BMI, $\mathrm{CrCl}$ and serum vancomycin concentration monitoring should play an important role in dosage adjustment in individual patients.

\section{Conclusions}

Our results suggest that serum vancomycin concentration decreases progressively with increasing BMI and the increase in $\mathrm{CrCl}$ in adult patients. Therefore, dose adjustment should be based on $\mathrm{BMI}$ and $\mathrm{CrCl}$ for safe and effective use of vancomycin in adult patients. The trough concentration of vancomycin should be continuously monitored for patients with $\mathrm{BMI} \geq 24 \mathrm{~kg} / \mathrm{m}^{2}$. Further research to confirm this negative association is needed.

\section{Abbreviations \\ APACHE: Acute Physiology and Chronic Health Evaluation; BMl: Body mass index; Cl: Confidence interval; CL: Clearance; CrCl: Creatinine clearance; EMIT: Enzyme multiplied immunoassay technique; GFR: Glomerular filtration rate; IDSA: Infectious Disease Society of America; MRSA: Methicillin-resistant Staphylococcus aureu; Scr: Serum creatinine concentration; TDM: Therapeutic drug monitoring; Vd: Volume of distribution; WHO: World Health Organization}

\section{Acknowledgements}

Not applicable.

\section{Authors' contributions}

YYP conceived and designed the study, participated in the clinical data collection and writing the manuscript. XMH and XYY performed experiments and participated in data collection. FJW and XFY performed data analysis and prepared the preliminary results of the manuscript. XYD was a major contributor in writing the manuscript. WJW participated in data analysis and interpretation and critically reviewed the manuscript. All authors read and approved the final manuscript.

\section{Funding}

This work was supported by grants from the National Natural Science Foundation of China (Grant No. 81703532, 81902320 and 81701490). The funders had no role in study design, data collection, analysis or interpretation of the data, preparation of the manuscript or decision to publish the results.

\section{Availability of data and materials}

The datasets used and/or analyzed during the current study are available from the corresponding author on reasonable request.

\section{Ethics approval and consent to participate}

This study was approved by decisions of the Ethics Committee of the Affiliated Changzhou No. 2 People's Hospital of Nanjing Medical University. The data used in this study was anonymised before its use.

Consent for publication

Not applicable.

Competing interests

The authors declare that they have no competing interests. 


\section{Author details}

'Department of Pharmacy, the Affiliated Changzhou No. 2 People's Hospital of Nanjing Medical University, Changzhou 213000, China. ${ }^{2}$ Department of Gastroenterology, the Affiliated Changzhou No. 2 People's Hospital of Nanjing Medical University, Changzhou 213000, China. ${ }^{3}$ Department of neonatology, Children's Hospital of Soochow University, Suzhou 215000, China. ${ }^{4}$ Department of Pharmacy, Children's Hospital of Soochow University, Suzhou 215000, China. ${ }^{5}$ Department of Pharmacy, The Affiliated Suzhou Hospital of Nanjing Medical University, Suzhou 215000, China.

Received: 30 September 2019 Accepted: 3 May 2020

Published online: 13 May 2020

\section{References}

1. Butler-Laporte G, De L'Étoile-Morel S, Cheng MP, McDonald EG, Lee TC. MRSA colonization status as a predictor of clinical infection: a systematic review and meta-analysis. J Inf Secur. 2018;77(6):489-95.

2. Pai MP, Neely M, Rodvold KA, Lodise TP. Innovative approaches to optimizing the delivery of vancomycin in individual patients. Adv Drug Deliv Rev. 2014;77:50-7.

3. Rybak MJ, Lomaestro BM, Rotschafer JC, Moellering RC, Craig WA, Billeter M, Dalovisio JR, Levine DP. Vancomycin therapeutic guidelines: a summary of consensus recommendations from the infectious diseases Society of America, the American Society of Health-System Pharmacists, and the society of infectious diseases pharmacists. Clin Infect Dis. 2009;49(3):325-7.

4. Ji XW, Ji SM, He XR, Zhu X, Chen R, Lu W. Influences of renal function descriptors on population pharmacokinetic modeling of vancomycinin Chinese adult patients. Acta Pharmacol Sin. 2018;39(2):286-93.

5. Nelson NR, Morbitzer KA, Jordan JD, Rhoney DH. The impact of capping creatinine clearance on achieving therapeutic vancomycin concentrations in neurocritically III patients with traumatic brain injury. Neurocrit Care. 2019; 30(1):126-31.

6. Padgett $D$, Ostrenga A, Lepard L. Comparison of methods of estimating creatinine clearance in pediatric patients. Am J Health Syst Pharm. 2017; 74(11):826-30.

7. Romão CM, Pereira RC, Shimizu MHM, Furukawa LNS. N-acetyl-I-cysteine exacerbates kidney dysfunction caused by a chronic high-sodium diet in renal ischemia and reperfusion rats. Life Sci. 2019;231:116544.

8. Wang K, Kestenbaum B. Proximal tubular secretory clearance: a neglected partner of kidney function. Clin J Am Soc Nephrol. 2018;13(8):1291-6.

9. Gerchman F, Tong J, Utzschneider KM, Zraika S, Udayasankar J, McNeely MJ,

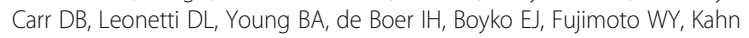
SE. Body mass index is associated with increased creatinine clearance by a mechanism independent of body fat distribution. J Clin Endocrinol Metab. 2009;94(10):3781-8.

10. Rutter WC, Hall RG, Burgess DS. Impact of total body weight on rate of acute kidney injury in patients treated with piperacillin-tazobactam and vancomycin. Am J Health Syst Pharm. 2019;76(16):1211-7.

11. Pokorná P, Šíma M, Černá O, Allegaert K, Tibboel D, Slanař O. Actual body weight-based vancomycin dosing in neonates. J Chemother. 2019;31(6): 307-12.

12. Vitolo E, Santini E, Salvati A, Volterrani D, Duce V, Bruno RM, Solini A Metabolic and hormonal determinants of glomerular filtration rate and renal hemodynamics in severely obese individuals. Obes Facts. 2016;9(5): 310-20.

13. Liu C, Bayer A, Cosgrove SE, Daum RS, Fridkin SK, Gorwitz RJ, Kaplan SL, Karchmer AW, Levine DP, Murray BE, Rybak MJ, Talan DA, Chambers HF, Infectious Diseases Society of America. Clinical practice guidelines by the Infectious Diseases Society of America for the treatment of methicillinresistant Staphylococcus aureus infections in adults and children. Clin Infect Dis. 2011;52(3):e18-55

14. Lodise TP, Lomaestro B, Graves J, Drusano GL. Larger vancomycin doses (at least four grams per day) are associated with an increased incidence of nephrotoxicity. Antimicrob Agents Chemother. 2008;52(4):1330-6.

15. Crass RL, Dunn R, Hong J, Krop LC, Pai MP. Dosing vancomycin in the super obese: less is more. J Antimicrob Chemother. 2018;73(11):3081-6.

16. Adane ED, Herald M, Koura F. Pharmacokinetics of vancomycin in extremely obese patients with suspected or confirmed Staphylococcus aureus infections. Pharmacotherapy. 2015:35(2):127-39.
17. Disease control Ministry of Health of the People's Republic of China. The guidelines of Chinese adult overweight and obesity prevention and control. Beijing: People's Medical Publishing House; 2006. p. 1-3.

18. Eknoyan G, Levin N. NKF-K/DOQI clinical practice guidelines: update 2000 Foreword Am J Kidney Dis. 2001;37(1 Suppl 1):S5-6.

19. Cockcroft DW, Gault MH. Prediction of creatinine clearance from serum creatinine. Nephron. 1976;16(1):31-41.

20. Estes KS, Derendorf $\mathrm{H}$. Comparison of the pharmacokinetic properties of vancomycin, linezolid, tigecyclin, and daptomycin. Eur J Med Res. 2010; 15(12):533-43.

21. Heble DE Jr, McPherson C, Nelson MP, Hunstad DA. Vancomycin trough concentrations in overweight or obese pediatric patients. Pharmacotherapy. 2013;33(12):1273-7.

22. https://www.who.int/news-room/fact-sheets/detail/obesity-and-overweight. Accessed 16 Feb 2018

23. Hayes A, Gearon E, Backholer K, Bauman A, Peeters A. Age-specific changes in $\mathrm{BMI}$ and $\mathrm{BMI}$ distribution among Australian adults using cross-sectional surveys from 1980 to 2008. Int J Obes. 2015;39(8):1209-16.

24. Hanley MJ, Abernethy DR, Greenblatt DJ. Effect of obesity on the pharmacokinetics of drugs in humans. Clin Pharmacokinet. 2010;49(2):71-87.

25. Bi J, Li X, Liu J, Chen D, Li S, Hou J, Zhou Y, Zhu S, Zhao Z, Qin E, Wei Z. Population pharmacokinetics of peginterferon a2a in patients with chronic hepatitis B. Sci Rep. 2017;7(1):7893.

26. Tanigawara Y, Sato R, Morita K, Kaku M, Aikawa N, Shimizu K. Population pharmacokinetics of Arbekacin in patients infected with methicillin-resistant Staphylococcus aureus. Antimicrob Agents Chemother. 2006;50(11):3754-62.

\section{Publisher's Note}

Springer Nature remains neutral with regard to jurisdictional claims in published maps and institutional affiliations.

Ready to submit your research? Choose BMC and benefit from:

- fast, convenient online submission

- thorough peer review by experienced researchers in your field

- rapid publication on acceptance

- support for research data, including large and complex data types

- gold Open Access which fosters wider collaboration and increased citations

- maximum visibility for your research: over $100 \mathrm{M}$ website views per year

At $\mathrm{BMC}$, research is always in progress.

Learn more biomedcentral.com/submissions 